\title{
Hubungan OAINS pada Pengobatan Dismenorea dengan Kejadian Dispepsia pada Mahasiswi Fakultas Kedokteran Universitas Andalas
}

\author{
Siti Dwiaulia Risnomarta ${ }^{1}$, Arnelis $^{2}$, Ermawati $^{3}$
}

\begin{abstract}
Abstrak
Dismenorea merupakan salah satu keluhan ginekologi tersering yang membawa pasien datang ke dokter. Dismenorea terjadi $40-80 \%$ dan $5-10 \%$ nya membutuhkan pengobatan. Obat anti inflamasi non steroid (OAINS) paling sering digunakan untuk pengobatan dismenorea primer. Namun efek samping sering terjadi terutama pada saluran cerna. Tujuan penelitian ini adalah untuk mengetahui hubungan OAINS sebagai pengobatan dismenorea dengan kejadian dispepsia pada mahasiswi Fakultas Kedokteran Universitas Andalas. Rancangan penelitian adalah analitik cross-sectional. Subjek penelitian berjumlah 62 orang yang diambil dengan menggunakan metode total sampling. Dari penelitian ini diperoleh jumlah responden yang mengalami dispepsia sebanyak 14 orang (22,6\%). Penelitian ini menilai OAINS (jenis,jumlah, dan kombinasi) pada pengobatan dismenorea dengan kejadian dispepsia. Derajat dispepsia yang dikeluhkan umumnya ringan. Hasil uji chi-square antara jenis OAINS pada pengobatan dismenorea dan kejadian dispepsia didapatkan $p=0,120$. Hasil uji chi-square antara jumlah OAINS pada pengobatan dismenorea dengan kejadian dispepsia didapatkan $p=1,00$. Hasil uji chi-square antara kombinasi OAINS pada pengobatan dismenorea dengan kejadian dispepsia didapatkan $p=0,125$. Berdasarkan hasil penelitian didapatkan bahwa tidak terdapat hubungan antara jenis, jumlah, dan kombinasi OAINS pada pengobatan dismenorea dengan kejadian dispepsia.
\end{abstract}

Kata kunci: dismenorea, OAINS, dispepsia

\section{Abstract}

Dysmenorrhea is one of most common gynecological complaint that bring the patients come to see doctor. Dysmenorrhea occurs $40-80 \%$ and 5-10\% need treatment. Non-steroidal anti-inflammatory drugs (NSAIDs) are the most common treatment for primary dysmenorrhea. The side effects of NSAIDs often occur, especially in gastointestinal. The objective of this study was to determine the relationship of NSAIDs in the treatment of dysmenorrhea and dyspepsia incident in female students of Faculty of Medicine of Andalas University. The design study is cross sectional analytic. The subject of this research were 62 students that taken by using total sampling method. This study found that the respondents who suffered dyspepsia were 14 (22.6\%). This study assessed NSAIDs (types, amounts, and combinations) in dysmenorrhea treatment that caused dyspepsia. Chi-square test resulted between types of NSAIDs in dysmenorrhea treatment and the incident of dyspepsia obtained $p=0.120$. The $p$ value in the relation between amounts of NSAIDs and the incident of dyspepsia is $p=1.00$. The resulted between the combinations of NSAIDs with the incident of dyspepsia is $p=0.125$. Based on the result, there is no relationship between the types, amounts and combinations of NSAIDs in the treatment of dysmenorrhea with the incident of dyspepsia.

Keywords: dysmenorrhea, NSAIDs, dyspepsia

Affiliasi penulis : 1. Pendidikan Dokter FK UNAND (Fakultas Kedokteran Universitas Andalas Padang), 2. Bagian IImu Penyakit Dalam FK UNAND/RS Dr. M. Djamil Padang, 3. Bagian Kebidanan FK

UNAND/RS Dr. M. Djamil Padang
Korespondensi $\quad: \quad$ Siti $\quad$ Dwiaulia Risnomarta, E-
mail:sidurisnomarta@gmail.com, Telp: 085280442924




\section{PENDAHULUAN}

Dismenorea berasal dari kata Yunani, yaitu dys yang berarti susah atau nyeri abnormal, meno yang berarti bulan, dan rea yang berarti aliran. ${ }^{1}$ Dismenorea didefinisikan sebagai menstruasi yang sulit atau haid yang nyeri yang dapat terjadi sebelum atau selama menstruasi berupa serangan ringan, kram pada bagian tengah, bersifat spasmodis yang dapat menyebar ke punggung atau paha bagian dalam dan dapat juga disertai muntah, diare, sakit kepala, sinkop dan nyeri kaki. ${ }^{2}$

Dismenorea merupakan salah satu keluhan ginekologi tersering yang membawa pasien datang ke dokter. Penanganan optimal dari keluhan ini tergantung pada penyebab dari dismenorea itu sendiri. Dismenorea dibagi menjadi primer (spasmodik) dan sekunder (kongesti). primer adalah nyeri saat menstruasi yang tidak berhubungan dengan kelainan organ pelvis. Dismenorea sekunder adalah nyeri saat menstruasi yang didasari oleh kelainan pada organ pelvis. $^{3}$

Sembilan puluh persen wanita yang datang ke pelayanan primer mengalami nyeri haid. ${ }^{3}$ Keluhan nyeri ini sering berhubungan dengan ketidakhadiran di sekolah, pekerjaan, atau kegiatan lainnya. ${ }^{4}$ Dismenorea primer umumnya dimulai 2 tahun setelah menstruasi pertama. ${ }^{5}$ Puncak insiden dismenorea primer terjadi pada akhir masa remaja (adolescence) dan di awal usia 20-an, insiden dismenore pada remaja dilaporkan sekitar 92\%. Insiden ini menurun seiring dengan bertambahnya usia dan meningkatnya kelahiran. ${ }^{6}$

Penderita cenderung mencari pengobatan untuk menghilangkan keluhan dismenorea. Obat anti inflamasi non steroid (OAINS) dan kontrasepsi oral kombinasi adalah pengobatan utama dismenorea. obat-obatan ini memiliki mekanisme kerja yang berbeda. $^{2}$

OAINS mengurangi nyeri haid dengan menurunkan tekanan intra uterin dan menurunkan level prostaglandin F2 alpha pada cairan menstruasi. OAINS memberikan perbaikan pada $80-85 \%$ pasien yang diteliti. $^{7}$

Obat anti inflamasi non steroid memegang peranan penting dalam menanggulagi keluhan pada dismenorea primer ini, termasuk indometasin, ibuprofen, dan naproksen. Kurang lebih $70 \%$ penderita dapat sembuh atau mengalami banyak perbaikan. ${ }^{8}$

Efek samping yang terjadi karena penggunaan OAINS tidaklah ringan, terutama efek pada saluran cerna. Efek samping tersebut dikaitkan dengan kerja obat tersebut menghambat biosintesis prostaglandin yang merupakan substansi penting pada beberapa organ. Secara umum OAINS menyebabkan efek samping pada tiga sistem organ yaitu saluran cerna, ginjal dan hati. Efek samping tersering adalah induksi tukak peptik yang gambaran klinisnya berupa keluhan dispepsia. $^{9}$

Dispepsia adalah suatu sindroma atau kumpulan beberapa gejala berupa nyeri atau rasa tidak nyaman di epigastrium, kembung, mual, muntah, rasa cepat kenyang atau perut rasa penuh, dan rasa seperti menyesak dari epigastrium ke atas. ${ }^{10}$ Dispepsia merupakan salah satu masalah pencernaan yang paling umum ditemukan dan dilaporkan bahwa prevalensi dispepsia pada populasi umum berkisar antara $12-59 \%$ dengan prevalensi rata-rata $31 \%{ }^{11}$

Di Negara Barat prevalensi dispepsia berkisar antara $7-41 \%$ dan yang berobat hanya $10-20 \%$. Diperkirakan bahwa hampir 30\% pasien yang berobat ke dokter umum dan $60 \%$ pasien di klinik gastroenterologi merupakan penderita dispepsia. ${ }^{10}$

Penelitian yang dilakukan oleh Marjoribanks et al pada wanita dengan dismenorea primer ditemukan bahwa OAINS secara signifikan lebih efektif untuk menghilangkan rasa sakit dibandingkan plasebo, meskipun efek sampingnya juga dirasakan. ${ }^{5}$ Penggunaan OAINS merupakan salah satu faktor penyebab dari sindroma ini. Sekitar $10-20 \%$ pasien yang mendapat OAINS akan mengalami dispepsia, prevalensi kejadiannya berkisar $5-50 \%{ }^{12}$

\section{METODE}

Penelitian ini adalah analitik observasional dengan desain cross sectional. Pengambilan besar sampel ditentukan dengan total sampling.

Responden penelitian berjumlah 555 orang yang berasal dari angkatan 2010 sebanyak 178 orang, angkatan 2011 sebanyak 180 orang dan angkatan 2012 sebanyak 197 orang. Subjek penelitian adalah responden yang mengalami dismenorea dan menggunakan OAINS sebagai pengobatan. 
Kriteria inklusi adalah: 1.mahasisiwi yang mengalami dismenorea dan menggunakan OAINS sebagai pengobatan, 2 . tidak sedang hamil, 3. bersedia mengikuti penelitian. Kriteria eksklusi adalah: 1. tidak menggunakan OAINS sebagai pengobatan dismenorea, 2. telah didiagnosa oleh dokter menderita penyakit pada pankres, hepatobilier maupun sistemik yang meliputi pankreatitis, tumor pankreas, hepatitis, kolesistitis, kolelitiasis, kanker hati, disfungsi sfingter oddi, diabetes melitus, penyakit tiroid dan gagal ginjal, 3. menggunakan OAINS untuk keluhan selain dismenorea. 4.tidak bersedia mengikuti penelitian.

\section{HASIL}

Subjek penelitian berjumlah 62, tetapi yang mengalami dispepsia sebanyak 14 orang (22,6\%). Tiga belas orang diantaranya mengalami dispepsia ringan. Asam mefenamat adalah yang terbanyak menyebabkan disepsia yaitu $78,5 \%$.

Hubungan jenis OAINS dengan kejadian dyspepsia pada pengobatan dismenorea dianalisa dengan chi-square test kemudian dibaca dengan Pearson Chi-square dan didapatkan nilai $\mathrm{p}=0,120$ yang menunjukkan tidak adanya hubungan antara dua hal tersebut (Tabel 1).

Tabel 1. Hubungan jenis OAINS dengan kejadian dispepsia pada pengobatan dismenorea.

\begin{tabular}{|c|c|c|c|c|c|c|c|}
\hline \multirow[t]{2}{*}{$\begin{array}{c}\text { COX- } \\
\text { nonselektif }\end{array}$} & \multicolumn{6}{|c|}{ Dispepsia } & \multirow[t]{2}{*}{$\mathbf{p}$} \\
\hline & $n$ & $\%$ & $\mathrm{n}$ & $\%$ & $\mathrm{n}$ & $\%$ & \\
\hline Parasetamol & 9 & 90,0 & 1 & 10,0 & 10 & 100 & 0,120 \\
\hline Metampiron & 1 & 33,3 & 2 & 66,7 & 3 & 100 & \\
\hline $\begin{array}{l}\text { Asam } \\
\text { mefenamat }\end{array}$ & 38 & 77,5 & 11 & 22,5 & 49 & 100 & \\
\hline Jumlah & 48 & 77,4 & 14 & 22,6 & 62 & 100 & \\
\hline
\end{tabular}

Hasil uji statistik hubungan jumlah OAINS dengan kejadian dispepsia pada pengobatan dismenorea menggunakan chi-square test dan dibaca dengan Fisher's Exact Test menunjukkan tidak adanya hubungan antara kedua hal tersebut (Tabel 2).

Tabel 2. Hubungan jumlah OAINS dengan kejadian dispepsia pada pengobatan dismenorea

\begin{tabular}{cccccccc}
\hline $\begin{array}{c}\text { Jumlah } \\
\text { OAINS }\end{array}$ & \multicolumn{1}{c}{ Tidak } & \multicolumn{2}{c}{ Ya } & \multicolumn{2}{c}{ Jumlah } & $\mathbf{p}$ \\
\hline \multirow{2}{*}{ < 3 butir } & 47 & 77 & 14 & 23 & 61 & 100 & $\mathbf{1}, 000$ \\
$>=3$ butir & 1 & 100 & 0 & 0 & 1 & 100 & \\
\hline Jumlah & 48 & 77,4 & 14 & 22,6 & 62 & 100 & \\
\hline
\end{tabular}

Hubungan kombinasi OAINS dengan kejadian dispepsia pada pengobatan dismenorea dianalisa dengan chi-square test kemudian dibaca dengan Fisher's Exact Test dan didapatkan nilai $\mathrm{p}=0,125$ yang menunjukkan tidak adanya hubungan antara keduanya (Tabel 3).

Tabel 3. Hubungan kombinasi OAINS dengan kejadian dispepsia pada pengobatan dismenorea

\begin{tabular}{cccccccc}
\hline $\begin{array}{c}\text { Kombinasi } \\
\text { OAINS }\end{array}$ & Tidak & Ya & Jumlah & $\mathbf{p}$ \\
\hline \multirow{2}{*}{ Ya } & $\mathrm{n}$ & $\%$ & $\mathrm{n}$ & $\%$ & $\mathrm{n}$ & $\%$ & \\
Tidak & 47 & 33,3 & 2 & 66,7 & 3 & 100 & $\mathbf{0 , 1 2 5}$ \\
\hline Jumlah & 48 & 79,7 & 12 & 20,3 & 59 & 100 & \\
\hline
\end{tabular}

\section{PEMBAHASAN}

Kejadian dispepsia pada penggunakan OAINS sebagai pengobatan dismenorea.

Penelitian yang dilakukan oleh Marjoribanks et al tahun 2004 pada wanita yang mengalami dismenorea primer didapatkan bahwa OAINS efektif mengobati keluhan tersebut meskipun terdapat efek samping yaitu dispepsia. ${ }^{5}$ Wolfe menyatakan bahwa OAINS merupakan salah satu penyebab sindroma dispepsia, sekitar $10-20 \%$ pasien yang menggunakan OAINS akan mengalami sindroma tersebut. ${ }^{12}$ Pada penelitian ini subjek yang mengalami dispepsia berjumlah 14 orang $(22,6 \%)$.

\section{Derajat keluhan dispepsia}

Subjek yang menggunakan OAINS saat dismenorea yaitu suatu penggunaan jangka pendek didapatkan derajat dispepsia bersifat ringan (92,9\%) 
dan sedang $(7,1 \%)$. Hal ini sejalan dengan penelitian yang dilakukan oleh Bjarnason pada tahun 2012 yang mendapatkan bahwa pada pasien yang menggunakan OAINS jangka pendek (kurang dari 14 hari) derajat keluhan dispepsia yang dirasakan adalah ringan hingga sedang. ${ }^{13}$

\section{Hubungan jenis OAINS dengan kejadian dispepsiapada pengobatan dismenorea}

Menurut Coco, Pengobatan lini pertama yang paling tepat untuk dismenore primer adalah OAINS. ${ }^{15}$ Zhang dan Li Wan menyebutkan bahwa 4 jenis OAINS (Naproksen, ibuprofen, asam mefenamat dan aspirin) efektif unutk mengobati dismenorea primer. ${ }^{16}$ Sebuah penelitian tentang nyeri (pain study) yang dilakukan oleh Moore menilai toleransi dari ibuprofen (1200 $\mathrm{mg} /$ hari), aspirin (3 g/hari) dan parasetamol (3 g/hari). Didapatkan dari 8677 orang yang diteliti, tingkat efek samping yang terjadi dilaporkan adalah 18,7\% dari pasien yang mengunakan aspirin, 13,7\% dari yang menggunakan ibuprofen dan $14,5 \%$ dari yang mendapatkan parasetamol. Secara keseluruhan disebutkan bahwa terdapat 6 kasus perdarahan saluran cerna yang tidak serius: 4 kasus terjadi pada grup parasetamol dan 2 kasus pada grup aspirin. ${ }^{17}$

Penelitian ini mendapatkan asam mefenamat adalah OAINS terbanyak yang menyebabkan dispepsia yaitu 78,5\%. Asam Mefenamat sering digunakan untuk pengobatan jangka pendek seperti dismenorea. Dosis asam mefenamat adalah 2-3 kali 250-500 mg sehari. Efek samping terhadap saluran cerna sering timbul misalnya dispepsia, diare sampai berdarah dan gejala iritasi lain terhadap mukosa lambung. ${ }^{17}$

Parasetamol sedikit menyebabkan dispepsia pada penelitian ini, karena parasetamol tidak bersifat asam dan merupakan penghambat biosintesis $P G$ yang lemah. Parasetamol ditoleransi dengan baik dan insiden efek samping pada saluran cerna rendah. ${ }^{17}$

Pada penelitian ini didapatkan tidak adanya hubungan antara jenis OAINS dengan kejadian dispepsia pada pengobatan dismenorea $(p=0,120)$. Hal ini terjadi karena penggunaan OAINS pada dismenorea adalah penggunaan jangka pendek yaitu hanya 1-3 hari.

\section{Hubungan jumlah OAINS dengan kejadian dispepsiapada pengobatan dismenorea \\ Dari penelitian didapatkan bahwa 61 orang} (98,4\%) menggunakan OAINS kurang dari 3 butir saat dismenorea dan yang mengalami dispepsia adalah 14 orang (23\%). Hasil uji statistik menunjukkan tidak adanya hubungan antara jumlah OAINS dengan kejadian dispepsia pada pengobatan dismenorea $(p=1,000)$.

OAINS merupakan salah satu kelompok obat yang banyak diresepkan dan juga digunakan tanpa resep. ${ }^{9}$ Campbel dan McGrath menyebutkan bahwa remaja putri yang mengalami nyeri haid ringan dan durasi nyeri yang pendek sering menggunakan obat bebas untuk mengobati keluhan tersebut. Lebih dari setengahnya (56\%) menggunakan obat bebas yang kurang dari rekomendasi harian maksimum. ${ }^{18}$

Harel menyebutkan bahwa pengobatan paling efektif untuk dismenorea primer dimulai pada hari 1-2 sebelum menstruasi karena dismenorea biasanya sembuh pada hari ke 2-3 menstruasi. Oleh karena itu pengobatan jangka pendek tersebut membatasi perkembangan efek samping OAINS. ${ }^{19}$

\section{Hubungan kombinasi OAINS dengan kejadian dispepsia pada pengobatan dismenorea.}

Penggunaan kombinasi OAINS adalah salah satu faktor yang memudahkan terjadinya gangguan saluran cerna. OAINS bekerja menghambat biosintesa prostaglandin yang merupakan substansi penting dalam menjaga keutuhan mukosa saluran cerna. Oleh karena itu, penggunakan lebih dari satu jenis OAINS akan mempermudah terjadinya efek samping tersebut. $^{20}$

Pada penelitian ini didapatkan 2 dari 3 subjek yang menggunakan kombinasi OAINS saat dismenorea mengalami dispepsia dan pada uji statistik didapatkan bahwa tidak terdapat hubungan antara kombinasi OAINS dengan kejadian dispepsia pada pengobatan dismenorea $(p=0,125)$.

Bennet dan Brown menyebutkan bahwa pemberian kombinasi OAINS sebaiknya dihindari, sebab manfaatnya tidak akan meningkat bahkan efek sampingnya bertambah. ${ }^{21}$ 


\section{KESIMPULAN}

Hanya sedikit kejadian dispepsia yang terjadi karena OAINS pada pengobatan dismenorea. Dispepsia karena OAINS pada pengobatan dismenorea umumnya ringan. Tidak terdapat hubungan antara jenis OAINS dengan kejadian dispepsiapada pengobatan dismenorea. Tidak terdapat hubungan antara jumlah OAINS dengan kejadian dispepsiapada pengobatan dismenorea. Tidak terdapat hubungan antara kombinasi OAINS dengan kejadian dispepsiapada pengobatan dismenorea.

\section{DAFTAR PUSTAKA}

1. Calis KA. Dysmenorrhea. 2011 (diunduh 19 September 2012). Tersedia dari: URL: HYPERLINK: http://emedicine.medscape.com/ article/253812-overview\#a0101

2. Morgan G, Hamilton C. Obstetri dan ginekologi: panduan praktik. Jakarta: EGC; 2009. hlm. 180-6.

3. Lefebvre G, Pinsonneault $O$, Antao V, Black A, Burnett $\mathrm{M}$, Feldman $\mathrm{K}$, et al. Primary dysmenorrhea consensus guideline. J Obstet Gynaecol Canada. 2005;169:1117-30.

4. Burnett MA, Antao V, Black A, Feldman $K$, Grenville A, Lea $R$, et al. Prevalence of primary dysmenorrhea in Canada. J Obstet Gynaecol Canada. 2005; 27(8):765-70.

5. Marjoribanks, J, Proctor ML, Farquhar C, Derks RS. Nonsteroidal anti inflammatory drugs for primary dysmenorrhoea. Cochrane Database Syst. Rev. 1. 2004. CD001751.

6. Anurogo D. Segala sesuatu tentang nyeri haid. 2008 (diunduh 21 Februari 2013). Tersedia dari: URL: HYPERLINK http://www.kabarindonesia. com/berita.php?pil=3\&dn=20080619164804

7. Livshits A, Seidman DS. Role of non-steroidal antiinflammatory drugs in gynecology. Journal Pharmaceuticals. 2010; 3:2082-9.

8. Simanjuntak P. Dismenorea. Dalam: Winkjosastro $H$, Saifudin AB, Rachimhadhi $T$, editor (penyunting). Ilmu Kandungan. Edisi ke-2. Jakarta: PT Bina Pustaka Sarwono Prawihardjo;2009. hlm.
229-34.

9. Wilmana PF, Gan S. Analgesik-antipiretik analgesik anti-inflamasi nonsteroid dan obat gangguan sendi lainnya. Dalam: Gunawan SG, Setiabudy R, Nafrialdi, Elysabeth, editor (penyunting). Farmakologi dan Terapi. Edisi ke-5. Jakarta: Balai Penerbit FKUI; 2007. hlm. 230-46.

10. Djojoningrat D. Dispepsia fungsional. Dalam: Sudoyo AW, Setiyohadi B, Alwi I, Simadibrata M, Setiati S, editor (penyunting). Buku Ajar IImu Penyakit Dalam. Jilid 1. Edisi ke-5. Jakarta: Interna Publishing; 2009. hlm. 529-33.

11. Curioso WH, Donaires MN, Bacilio ZC, Ganoza GC, Leon BR. Prevalencia y asociación de la dispepsia y el síndrome de intestino irritable en una comunidad de la Selva Peruana. Revista de Gastroenterología del Perú. 2002; 22(2):129-40

12. Wolfe MM, Lichtenstein DR, Singh G. Gastrointestinal toxicity of nonsteroidal antiinflammatory drugs. The New England Journal of Medicine. 1999;340:(24):1888-99.

13. Bjarnason I. Gastrointestinal safety of NSAIDs and over-the-counter analgetics. The International Journal of Clinical Practice. 2013;178:37-42.

14. Goodman, Gilman. Analgesic-antipyretic and antiinflammatory agents; pharmacotherapy of gout. Dalam: Brunton L, Parker K, Blumenthal D, Buxton I, editor (penyunting). Manual of Pharmacology and Therapeutics. New York: Mac Graw Hill Inc; 2007. hlm. 430-61.

15. Coco AS. Primary dysmenorrhea. American family physician. 1999; 60(2):489-96.

16. Zhang WY, Li Wan PA. Efficacy of minor analgesics in primary dysmenorrhoea: a systematic review. Br. J. Obstet. Gynaecol. 1998;105:780-9.

17. Moore N. Forty years of ibuprofen use. Int $\mathrm{J}$ Clin Pract. 2003; 135: 28-31.

18. Campbell MA, McGrath PJ. Non-pharmacologic strategies used by adolescents for the management of menstrual discomfort. Clin J Pain. 1999; $15: 313$.

19. Harel Z. Dysmenorrhea in adolescents and young adults: etiology and management. $J$ Pediatr 
Adolesc Gynecol. 2006;19:363-71.

20. Akil H. Tukak duodenum. Dalam: Sudoyo AW, Setiyohadi B, Alwi I, Simadibrata M, Setiati S, editor (penyunting). Buku Ajar IImu Penyakit
Dalam. Jilid 1. Edisi ke-5. Jakarta: Interna Publishing; 2009. hlm. 523-8.

21. Bennett PN, Brown MJ. Clinical Pharmacology. Edisi 9. Churchill Livingstone; 2004. 